\title{
Clinical Trial Material
}

National Cancer Institute

\section{Source}

National Cancer Institute. Clinical Trial Material. NCI Thesaurus. Code C142449.

A term of art referring to the entire set of goods and equipment that are given to a researcher by the trial sponsor, in order to carry out the clinical trial. 